\title{
Pregnancy with Paroxysmal Nocturnal Hemoglobinuria (PNH) : A Case Report
}

\author{
TABASSUM PARVEEN ${ }^{1}$, FIROZA BEGUM ${ }^{2}$, NAHREEN AKHTER ${ }^{3}$
}

\begin{abstract}
:
Paroxysmal nocturnal hemoglobinuria $(P N H)$ resulting from failure of expression of anchoring protein glycosylphosphatidylinositol (GPI), is an uncommon acquired hemolytic anemia manifested by hemoglobinuria, abdominal pain, smooth muscle dystonia, fatigue and thrombosis. Pregnancy with PNH is rare, and studies showed an increased risk of foetomaternal complications even death due to worsening cytopenias and consequent thrombosis. Here we reported a case of PNH in pregnancy. Mrs. Nasima, aged 25 years, para: 0+0, was diagnosed as a case of PNH by flowcytometry analysis on granulocytes about 1 year 3months back. Her pregnancy was no planned and she was not on antenatal care but took consultation from haematologist time to time. Her Hb level was 7-8gm/dl throughout pregnancy and needed repeated blood transfusion for anaemia. She was referred from a nearby clinic at 37 weeks of pregnancy with PROM and labour pain to the Foetomaternal medicine wing of Obs \& Gynae department of BSMMU. On admission she was mildly icteric. She was treated with steroid as per consultation of haematologist. Due to failure of progress of labour emergency caesarean section was done under spinal anesthesia and a low birth weight female baby of $1.6 \mathrm{~kg}$ was delivered. One unit of blood transfusion was given post operatively.
\end{abstract}

Key words: PNH, Pregnancy, Flowcytometry

\section{Introduction:}

Paroxysmal nocturnal haemoglobinuria $(\mathrm{PNH})$ is an uncommon acquired hemolytic anaemia that often manifests with haemoglobinuria, abdominal pain, smooth muscle dystonia, fatigue and thrombosis. It is a rare disease with prevalence approximately 1-10 per million people. Though rare, but it is seen occasionally in pregnancy as young adults, especially women of childbearing age are commonly the victims of the condition. ${ }^{1}$

The disease results from a mutation in the phosphatidylinositol glycan A (PIGA) gene of haematopoietic stem cells in bone marrow. This gene encodes anchoring protein glycosylphosphatidylinositol (GPI). Mutation results into failure of the expression of the GPI on the cell membrane. ${ }^{2}$ As a result several proteins that anchor to GPI on the cell membrane to protect the cells from destruction by the complement system cannot exert their function. The main proteins that protect blood cells from destruction are decay-accelerating factor (DAFI CD55). This DAF/CD55 disrupts formation of C3convertase, and protectin (CD59/MIRL/MAC-IP), which normally binds with the membrane attack complex and prevents $\mathrm{C} 9$ from binding to the cell and thereby prevent complement activation. ${ }^{3}$ In $\mathrm{PNH}$ absence of the complement inactivating proteins due to GPI deficiency on peripheral blood cells leads to complement activation and thereby haemolysis.

The term "nocturnal" refers to the belief that haemolysis is triggered by acidosis during sleep and activates complement to cause haemolysis at night. However, this observation was later disproved. Haemolysis has been shown to occur throughout the day and is not actually paroxysmal, but the urine concentrated overnight produces the dramatic change in color. Only a minority have the telltale red urine in the morning. ${ }^{3}$

1. Associate Professor, Foetomaternal Medicine Wing Department of Obstetrics \& Gynaecology, Banga Bandhu Sheikh Mujib Medical University, Bangladesh

2. Professor, Foetomaternal Medicine Wing, Department of Obstetrics \& Gynaecology, Banga Bandhu Sheikh Mujib Medical University, Bangladesh

3. Associate Professor, Fetomaternal Medicine Wing, Department of Obstetrics \& Gynaecology, Banga Bandhu Sheikh Mujib Medical University, Bangladesh 
Pregnancy in women with $\mathrm{PNH}$ is rare, and available studies showed an increased risk of complications for both mother and fetus, leading to high maternal and foetal mortality rates. Worsening cytopenias may complicate the management of pregnancy but the main concern is the occurrence of thrombosis, which is responsible for the high mortality rates in pregnant $\mathrm{PNH}$ patients. In a recent review of 23 clinical reports published between 1965 and 2005 involving 43 women with $\mathrm{PNH}$ showed maternal and fetal mortality rates $11.6 \%$ and $7.2 \%$, respectively ${ }^{4}$. Venous thrombotic events (VTEs) were the major cause of maternal death. ${ }^{4}$ Here we reported a case of $\mathrm{PNH}$ in pregnancy recently managed in Foetomaternal medicine wing in the department of Obstetrics \& Gynaecology, Bangabandhu Sheikh Mujib Medical university (BSMMU). Furthermore, the obstetric literature on $\mathrm{PNH}$ in pregnancy is reviewed.

\section{Case:}

Mrs. Nasima, aged 25 years, para: 0+0, a housewife of middle class family hailing from Maghbazar, Dhaka got herself admitted in Foetomaternal medicine wing of Obstetrics and Gynaecology Department of BSMMU on $25^{\text {th }}$ March, 2014 at 37 weeks pregnancy with per-vaginal watery discharge for 4 hours and lower abdominal pain for 1 hour. She was diagnosed as a case of PNH about 1 year and 3 months back when she developed fever with extreme fatigue, anorexia, nausea, jaundice and dark colouration of the urine. On investigation haemoglobin level was found $7 \mathrm{gm} / \mathrm{dl}$ and was referred to Rajshahi Medical College where she was admitted and treated with transfusion of 3 units of blood. But 1 month later she again had same complains. This time she attended and subsequently admitted in haematology department of BSMMU in January 2013. Here on evaluation her $\mathrm{Hb}$ level was found $6.1 \mathrm{gm} / \mathrm{dl}$, ESR $80 \mathrm{~mm}$ in $1^{\text {st }}$ hour, RBC count $1.66 \mathrm{~m} / \mu \mathrm{l}, \mathrm{MCV} 112 \mathrm{fl}, \mathrm{PCV} 18.6 \%, \mathrm{MCH} 36.7 \mathrm{pg}, \mathrm{MCHC}$ $32.8 \mathrm{~g} / \mathrm{dl}$, reticulocyte count $8 \%$ indicating combined deficiency anaemia with prominent macrocytosis. Her platelet and white blood cell count was normal with mature distribution having few hypersegmented neutrophils. Iron profile showed features of iron deficiency anemia. Bilirubin level was 1.4mg/dl, SGPT was normal, Direct and indirect Coomb's tests were negative. Subsequently bone marrow examination was done which showed myeloid erythroid hyperplasia. Her urine report showed excess sediment. Urinary haemosiderine was present and Ham's test was negative. She was suspected as a case of $\mathrm{PNH}$. For confirmation of the diagnosis a sample of blood was sent to a neighboring country where flowcytometry analysis was done on granulocytes. The report showed CD55 + ve cell count $64.36 \%$ and CD59 +ve cell count $67.55 \%$ which confirmed the diagnosis of $\mathrm{PNH}$. She was given 3 units packed cell and was treated by oral prednisolone, folic acid and iron during her admission period of about 1 month. After discharge she was evaluated time to time by haematologist. The couple didn't practice any sort of contraception in their marital life of two and half years. Her this pregnancy was not planned, and she didn't seek any antenatal care but intermittently took consultation from hematology specialist. Her $\mathrm{Hb}$ level was maintained $7-8 \mathrm{gm} / \mathrm{dl}$ throughout pregnancy. She needed admission twice for blood transfusion in haematology department for anaemia. She was admitted to foetomaternal medicine wing of the department of Obstetrics and Gynaecology of BSMMU on 25th March 2014 with the complaints of abdominal pain and watery discharge for two days. On examination she was anxious looking with average body build, anaemic, mildly icteric. Her pulse rate was 92 beats/ minute and blood pressure was 150$90 \mathrm{~mm}$ of $\mathrm{Hg}$. On per abdominal examination symphysio-fundal height was $30 \mathrm{~cm}$. There was a single fetus in longitudinal lie with cephalic presentation and liquor volume was reduced. On pervaginal examination liquor was coming out and it was clear having no foul smell. Soon after admission she was given two ampoules injection dexamethasone $(5 \mathrm{mg})$ stat and tab. prednisolone $(20 \mathrm{mg}) 2+1+0$ started as per consultation of haematologist. Labour was augmented but failed to progress, so emergency caesarean section was arranged on the same day. Spinal anesthesia was given and a low birth weight female baby of $1.6 \mathrm{~kg}$ was delivered. One unit of blood transfusion was given post operatively. She was stable in post operative period. Rest of the postnatal period was uneventful and she was discharged on 30.03.14.

\section{Discussion:}

Review by Sophie et al of 27 pregnancies in 22 women with PNH in 10 French centers, between 1978 and 2008 noticed median age of the patients 21.5 years (range 13-41 years) at PNH diagnosis and 27 years (range 21-38 years) at pregnancy which is similar to the present case. In the same literature review vast majority i.e. in $74 \%$ cases pregnancy occurred in patients with a known cases of $\mathrm{PNH}$ and median 
time from diagnosis to pregnancy was 70.4 months (range 1-192 months). ${ }^{5}$ In the present case, time interval from diagnosis to pregnancy was 15 months. For the diagnosis of PNH several tests e.g. Flow cytometry, Fluorescent aerolysin (FLAERA)were done.Flow cytometry was one of thetests involved which detects CD59 and CD55 in patient's blood and absence or reduced level is diagnostic of PNH. In the present case Flowcytometry analysis was done where both the level were reduced which confirmed the diagnosis of $\mathrm{PNH}$. Available evidences showed increased risk of maternal and fetal morbidities and mortalities in $\mathrm{PNH}$ with pregnancy. In a recent literature review of 43 women with $\mathrm{PNH}$ in pregnancy between 1965 and 2005 maternal and fetal mortality rates was found $11.6 \%$ and $7.2 \%$, respectively. ${ }^{4}$ Paroxysmal intravascular haemolysis with anaemia, neutropenia, thrombocytopenia, thrombotic tendency particularly venous thrombosis or embolism in cerebral or intraabdominal veins and increased susceptibility to infections are found to be responsible factors for higher maternal complications. ${ }^{4,6}$ Available evidences showed that cytopenia and subsequent repeated blood transfusion was mostly responsible for maternal complications. Sophie in the literature review found 15 cases of cytopenias, 5 cases of hemolysis and 1 case of both cytopania and hemolysis at the time of the diagnosis of $\mathrm{PNH} .{ }^{5} \mathrm{Anju}$ et al reported a case of $\mathrm{PNH}$ who needed multiple blood transfusions during antenatal period and developed sepsis with acute renal failure and posterior reversible encephalopathy on 3rd weeks of postpartum. ${ }^{7}$ Anabela Melo et al reported 3 cases of PNH in pregnancy all of whom needed repeated blood transfusion for moderate to severe degree anemia. ${ }^{8}$ One patient developed a longitudinal sinus thrombosis in brain at 37 weeks and was treated with unfractionated intravenous heparin and one patient had recurrent epistaxis and preterm labour at 30 weeks. Regarding this patient, she had severe anaemia during pregnancy and needed repeated blood transfusion in antenatal period. She also had leucopenia. Pregnancy with PNH needs close follow up of the platelet count and should be maintained above $30 \times 10 \% / L$ throughout the pregnancy and above $50 \times 10^{9} / \mathrm{L}$ near term to minimize the risk of bleeding and need for platelet transfusion. ${ }^{9}$ Luckily this patient had normal platelet count throughout pregnancy and had no thrombotic events or infections during pregnancy and post-partum period. She was also not on any antithrombotic agents as her coagulation parameters were normal. $\mathrm{PNH}$ is associated with adverse perinatal outcome and the major cause of perinatal mortality is severe iatrogenic prematurity. Available evidences showed increased risk of preterm labour in patients with $\mathrm{PNH}^{4}{ }^{4}{ }^{10}$. Our patient though didn't have preterm labour but had premature rupture of the membranes (PROM) at 37 weeks. Baby had gross intrauterine growth restriction (IUGR) with birth weight only $1.6 \mathrm{~kg}$.

Treatment of $\mathrm{PNH}$ is mainly supportive in the form of blood transfusion, platelet transfusion, anti-coagulation therapy and steroid. ${ }^{11,12}$ However use of steroids in $\mathrm{PNH}$ is mostly empirical without randomized studies 13-15 and permanent therapy with steroid is not recommended. ${ }^{16}$ The incidence of clinically apparent venous thromboembolism during pregnancy in $\mathrm{PNH}$ is about $10 \%{ }^{17}$ and is associated with a high risk of mortality. ${ }^{18}$ The role of prophylactic anticoagulation for pregnant women with $\mathrm{PNH}$ has not been studied systematically. Line Bjorge et al suggested that the patients with $\mathrm{PNH}$ should be treated with lowmolecular-weight heparin throughout pregnancy with a change to unfractionated heparin before delivery and should be continued in the first few days after the delivery, before changing back to low-molecular-weight heparin for the rest of the postpartum period. ${ }^{1}$ Lifelong secondary prophylactic anticoagulation either with coumarins or heparins after a thromboembolic event is recommended in a study. ${ }^{19}$ Eculizumab, a humanised monoclonal antibody directed against the terminal complement protein $\mathrm{C5}$, which results in inhibition of complement-mediated cell lysis is the new therapeutic option for $\mathrm{PNH}^{20}$ Eculizumab reduces intravascular haemolysis, stabilizes haemoglobin levels, decreases transfusion requirements and improves quality of life in patients with $\mathrm{PNH}$. In some recent studies eculizumab was successfully administered to pregnant women, without adverse feto-maternal outcome. ${ }^{21,22}$ However, the data available so far have been collected from a small number of cases and eculizumab is still considered as pregnancy category C. Unfortunately, this monoclonal antibody is not currently available for use in our country. Despite all these treatment options the only potentially curative treatment of $\mathrm{PNH}$ currently available is bone marrow transplantation. ${ }^{23}$

Even though successful cases have been reported ${ }^{24}$ but after review of the available studies Line Bjorge et al suggested that pregnancy in patients with $\mathrm{PNH}$ 
should not be recommended due to its life threatening complications of thrombo-embolism. ${ }^{1}$ However, if the woman insists on pregnancy, she should be followed closely by both obstetricians and hematologists throughout the pregnancy. ${ }^{18,25,26,27}$ Unfortunately in our case, patient didn't take any consultation from obstetrician before pregnancy and even didn't have any ante natal care.

Conclusion: Pregnancy is a prothrombotic state and as $\mathrm{PNH}$ itself is associated with thrombosis during pregnancy, it is usually discouraged in such cases. Only a small number of cases have been reported in the literature. Management of pregnancy with $\mathrm{PNH}$ by a multidisciplinary team specially by foetomaternal specialist and haematologist is the key to successful clinical and obstetric outcomes. Here we presented a single case with $\mathrm{PNH}$ in pregnancy who received almost no antenatal care, presented as an emergency patient with premature rupture of the membranes and consequently an intrauterine growth restricted baby was delivered by LSCS. Neonatal outcome could be better if she had regular antenatal care under a highrisk pregnancy specialist.

\section{References:}

1. Bjorge L, Ernst P, Haram KO. Paroxysmal nocturnal haemoglobinuria in pregnancy. Acta Obstet Gynecol Scand. 2003; 82:1067-71.

2. Kumar, Vinay; Abbas, Abul K.; Fausto, Nelson; \& Mitchell, Richard N. Robbins Basic Pathology (8th ed.) Saunders Elsevier. p. 432 ISBN 978-14160-2973-1.

3. Parker C, Omine M, Richards S, et al.. "Diagnosis and management of paroxysmal nocturnal hemoglobinuria". Blood 2005;106 (12): 3699709. doi:10.1182/blood-2005-04-1717. PMC 1895106. PMID 16051736.

4. Fieni S, Bonfanti L, Gramellini D, Benassi L, Delsignore R. Clinical management of paroxysmal nocturnal hemoglobinuria in pregnancy: a case report and updated review. Obstet Gynecol Surv. 2006; 61(9):593-601.

5. Sophie de Guibert,Régis Peffault de Latour,Nathalie Varoqueaux, Hélène Labussière, Bernard Rio,Dominique Jaulmes,Jean-Richard Eveillard,Stéphanie Dulucq, Anne-Marie Stoppa, Didier Bouscary, François Girodon, Bernard Bonnotte, Djamila Laskri,Gérard Socié, Thierry
Lamy. Paroxysmal nocturnal hemoglobinuria and pregnancy before the eculizumab era: the French experience. Haematologica. 2011; 96(9): 12761283. doi: $10.3324 /$ haematol.2010.037531.

6. Ziakas PD, Poulou LS, Rokas GI, et al. Thrombosis in paroxysmal nocturnal hemoglobinuria: sites, risks, outcome. An overview. J Thromb Haemost. 2007; 5:642-5.

7. Anju Singh, Pooja Sikka, Vanita Suri, Neelam Agrawal, Seema Chopra, Bhupesh Kumar. Pregnancy in a patient with paroxysmal nocturnal hemoglobinuria. Int J Reprod Contracept Obstet Gynecol. 2014; 3(1): 285-287.

8. Anabela Melo, Rosário Gorgal-Carvalho,Joana Amaral, Maria Cristina Marques, Joaquim Andrade, João Tiago Guimarães and Mariana Guimarães. Clinical management of paroxysmal nocturnal haemoglobinuria in pregnancy: three case reports. Blood Transfus. Jan 2011; 9(1): 99-103. doi: 10.2450/2010.0024-10.

9. Cines DB, Blanchette VS. Immune thrombocytopenic purpura. N Engl J Med 2002; 346: 995-1008.

10. Paech MJ, Pavy TJG. Management of a parturient with paroxysmal nocturnal hemoglobinuria. Int J Obstet Anesth. 2004;13:188-91

11. Hillmen $\mathrm{P}$, Lewis $\mathrm{SM}$, Bessler M, Luzzatto L, Dacie JV.Natural history of paroxysmal nocturnal hemoglobinuria. N Engl J Med 1995; 333: 1253-8.

12. Packman $\mathrm{CH}$. Pathogenesis and management of paroxysmal nocturnal haemoglobinuria. Blood Rev. 1998; 12: 1-11.

13. Issaragrisil S, Piankijagum A, Tang-naitrisorana Y. Corticosteroids therapy in paroxysmal nocturnal hemoglobinuria. Am J Hematol 1987;25:77-83, DOI: 10.1002/ajh.2830250108

14. Bourantas K. High-dose recombinant human erythropoietin and low-dose corticosteroids for treatment of anemia in paroxysmal nocturnal hemoglobinuria. Acta Haematol 1994;91:62-65, DOI: 10.1159/000204254.

15. Zhao M, Shao Z, Li K, Chen G, Liu H, Zhang Y, $\mathrm{He} \mathrm{H}$, Shi J, He G, Chu Yang T. Clinical analysis of 78 cases of paroxysmal nocturnal hemoglobinuria diagnosed in the past ten years. 
Chin Med J (Engl) 2002;115:398-401. PMID: 11940374.

16. Parker C, Omine M, Richards S, Nishimura J, Bessler M, Ware R, Hillmen P, Luzzatto L, Young N, Kinoshita T, Rosse W, Socie G. Diagnosis and management of paroxysmal nocturnal hemoglobinuria. Blood 2005;106:3699-3709. DOI: 10. 1182/blood-2005-04-1717.

17. Ray JG, Burows RF, Ginsberg JS, Burrows EA. Paroxysmal nocturnal hemoglobinuria and the risk of venous thrombosis: review and recommendations for management of the pregnant and nonpregnant patient. Haemostasis. 2000; 30: 103-117.

18. Tichelli A, Socie G, Marsh J, et al. Outcome of pregnancy and disease course among women with aplastic anemia treated with immunosuppression. Ann Intern Med. 2002; 137: 164-172.

19. Hillmen $P$, Muus $P$, Dührsen $U$, Risitano AM, Schubert J, Luzzatto L, Schrezenmeier H, Szer J, Brodsky RA, Hill A, Socie G, Bessler M, Rollins SA, Bell L, Rother RP, Young NS. Effect of the complement inhibitor eculizumab on thromboembolism in patients with paroxysmal nocturnal hemoglobinuria. Blood. 2007; 110:41234128. DOI: 10.1182/blood-2007-06-095646.

20. Danilov AV, Smith $\mathrm{H}$, Craigo S, et al. Paroxysmal nocturnal hemoglobinuria ( $\mathrm{PNH}$ ) and pregnancy in the era of eculizumab. Leuk Res. 2009; 33:e4-e5.

21. Hillmen P, Young NS, Schubert J, et al. The complement inhibitor eculizumab in paroxysmal nocturnal hemoglobinuria. N Engl J Med. 2006; 355:1233-43.

22. Brodsky RA, Young NS, Antonioli E, et al. Multicenter phase 3 study of complement inhibitor eculizumab for the treatment of patients with paroxysmal nocturnal hemoglobinuria. Blood. 2008; 111:1840-7.

23. Raiola AM, Van Lint MT, Lamparelli T, Gualandi $F$, Benvenuto $F$, Figari $O$ et al. Bone marrow transplantation for paroxysmal nocturnal hemoglobinuria. Haematologica 2000; 85: 59-62.

24. Dalgaard J, Brinch L, Tjonnfjord GE. Paroksystisk nattlig hemoglobinuri-en sjelden sykdom med mangeansikter. [Paroxysmal nocturnal hemoglobinuria - a rare disease with many faces]. Tidsskr Nor Laegeforen. 2002; 122: 374-8.

25. Ray JG, Burows RF, Ginsberg JS, Burrows EA. Paroxysmal nocturnal hemoglobinuria and the risk of venous thrombosis: review and recommendations for management of the pregnant and nonpregnant patient. Haemostasis. 2000; 30: 103-17.

26. Bais J, von Pel M, dem Borne A, van der Lelie $\mathrm{H}$. Pregnancy and paroxysmal nocturnal hemoglobinuria. Eur J Obstet Gynecol Reprod Biol 1994; 53: 211-1.

27. Svigos JM, Norman J. Paroxysmal nocturnal haemoglobinuria and pregnancy. Aust N Z J Obstet Gynaecol 1994; 34: 10. 